to all who know the realities and reflect upon them, that without this unselfish and loyal collaboration the Council could not hope to perform adequately the tasks entrusted to them." Whether it is quite satisfactory that a great nation should depend on the charity of its best brains for this most necessary work is another question.

The ground covered by the Report is very wide, and deals with a great variety of research, but the admirable short accounts given in the text will enable the reader to follow the general trend of each piece of work. The Committee upon the Physiolog. of Vision is still at work on the special problems of the Fighting Services, general problems relating to vision such as glare and flicker, and the psychology of reading. Some of the work by Banister, Hartridge and Lythgoe on the latter subject was published in this journal (Brit. Jl. of Ophthal., Vol. XI, pp. 49, $321,192 \pi)$. Duke-Elder has also received a grant-in-aid for his work on the physiology of intra-ocular pressure, an account of which formed one of our monograph supplements. The same worker in company with J. R. Riddell has been working upon the effects on vision of industrial occupations involving the risk of eyestrain. Miss Vernon's work on summarizing, the methods used in the measurement of eye movements appeared in our March number of this vear.

In the introduction to the Report special attention is drawn to the successful work of the new machinery provided by the Committee of Civil Research in securing the discussion of problems affecting different parts of the United Kingdom or of the Empire, in the common light of both administrative experience and scientific knowledge.

The fresh opportunities thus provided for collaboration should be of great benefit to workers at home as well as to those in the Colonial Empire overseas.

We can assure our readers that they will not grudge the time spent in reading this most interesting Report.

\title{
Carl Koller and Cocaine
}

In the January-February number (Vol. VII, 1928) of Anesthesia and Analgesia will be found some interesting reminiscences by Koller on the first use of cocaine in eye surgery. Until 1884 the only known method of obtaining local anaesthesia was the Richardson ether spray, which, acting by freezing, was used for operations of short duration, such as the opening of whitlows, etc. At this time Koller was house surgeon at the Allgemeine Krankenhaus in Vienna; he had done research work in embryology, and 
had investigated the actions of various poisons on respiration, glandular secretion, and circulation. He was impressed by the unsuitability of general narcosis for ophthalmic operations, due to such sequelae as retching, vomiting and general restlessness. His first experiments were done with chloral, bromide, and morphia; but these researches led to no success, and the matter was temporarily laid aside.

About this time a young physiologist had, through the distress caused by a painful stump, after amputation of a thumb, become addicted to the use of morphia. He was under the care of Sigmund Freud, later to become famous as the author of psycho-analysis, and Breuer. These physicians tried to break their patient of the morphia habit by substituting cocaine, supplied by Merck of Darmstadt, the available supply of which at the time amounted to only a few grammes. Freud, in the summer of 1884, asked Koller to assist him in a series of experiments on the physiological systemic effects of cocaine. They took the alkaloid by the mouth, and, after allowing sufficient time to elapse for the drug to be absorbed into the circulation, conducted experiments on their muscular strength, fatigue, etc.

Niemann, in 1858 , first isolated the alkaloid from the coca leaves brought to Europe from Peru in the Austrian frigate Novara, on its scientific expedition, circumnavigating the globe; and it had been known, since the year 1860, that cocaine taken by the mouth caused numbness of the tongue.

Koller disposes of the fiction that he was led to the idea of the local value of cocaine as an anaesthetic by getting a drop splashed into his own eye. This was not the case. He instilled a solution of the drug into the eves of animals in the first place, and found that he obtained anaesthesia of the conjunctiva and cornea. Afterwards he repeated the experiments on himself, on colleagues, and on patients.

On September 15, 1884, he made his epoch-making discovery public by presenting a paper at the meeting of the German Oplrthalmological Society at Heidelberg; and in October of the same year he read a more elaborate paper on the subject before the Gesellschaft der Aertze of Vienna. At the same time one of his colleagues was engaged on experiments with cocaine as a local anaesthetic for laryngological cases.

In spite of repeated trials with other drugs cocaine easily holds the field as the best local anaesthetic for eye work; and although it is nearly 44 years since it was first used, and in spite of the advocacy of butyn, borocaine, etc., nothing more satisfactory has vet been found to take its place in ophthalmic surgery. It is of value to have this authoritative account at first hand of the work which led up to its discovery. 